\title{
Estimating Preferences for Wind Turbine Locations - A Critical Review of Visualisation Approaches
}

Hevia Koch, Pablo Alejandro; Ladenburg, Jacob

Link to article, DOI:

$10.2139 /$ ssrn.2848529

Publication date:

2016

Document Version

Publisher's PDF, also known as Version of record

Link back to DTU Orbit

Citation (APA):

Hevia Koch, P. A., \& Ladenburg, J. (2016). Estimating Preferences for Wind Turbine Locations - A Critical Review of Visualisation Approaches. Social Science Research Network (SSRN). USAEE Working Paper No. 16278 https://doi.org/10.2139/ssrn.2848529

\section{General rights}

Copyright and moral rights for the publications made accessible in the public portal are retained by the authors and/or other copyright owners and it is a condition of accessing publications that users recognise and abide by the legal requirements associated with these rights.

- Users may download and print one copy of any publication from the public portal for the purpose of private study or research.

- You may not further distribute the material or use it for any profit-making activity or commercial gain

- You may freely distribute the URL identifying the publication in the public portal

If you believe that this document breaches copyright please contact us providing details, and we will remove access to the work immediately and investigate your claim 


\title{
Estimating preferences for wind turbine locations - a critical review of visualisation approaches
}

\author{
Pablo Hevia-Koch ${ }^{\mathrm{a}}$, Jacob Ladenburg ${ }^{\mathrm{b}}$ \\ ${ }^{a}$ Department of Management Engineering, Technical University of Denmark, Denmark \\ ${ }^{b}$ KORA, Danish Institute for Local and Regional Government Research, Denmark
}

\begin{abstract}
As the amount of wind energy installed capacity keeps growing, in Europe and the world in general, the siting of wind projects near population or recreational centres becomes a frequent possibility. Therefore, it is of high interest for policy makers and developers to be able to quantify the effect of wind projects on public acceptance.
\end{abstract}

Currently, one of the main drivers for acceptance of wind turbines by the public is their level of visual impacts. While recent studies have focused on estimating the welfare loss of visual impacts from wind turbines, a large share of the applied studies have used no or very simple visualisation of the actual visual impacts at stake. These studies thus rely on the cognitive skills of the respondents to imagine wind turbines of different sizes and locations; and on the prior experience people have had with wind turbines.

By extending the economic model of perceived quality developed by Blomquist and Whitehead (1998), this paper provides a theoretical argument for the need of visualisations when describing valuation scenarios for respondents, as well as the relevance to correctly define the amount of attributes of the good to be represented on the visualisation, and which visualisation techniques to utilise. Afterwards, we propose a framework for classifying different visualisation types and utilise it to classify recent studies regarding wind turbines acceptance, highlighting the lack of visualisations in recent studies, as well as the need to raise the bar on scenario descriptions for wind turbine visual impacts valuation.

Keywords: wind energy, stated preference studies, environmental valuation, landscape valuation, visualisations

\section{Introduction}

Fossil fuels have been the main energy generation source for many years, but concerns regarding $\mathrm{CO} 2$ emissions and climate change have motivated the search for alternative energy systems that can reduce the emission of greenhouse gasses. Energy goals across countries, as for example the Europe 2020 Climate and

Email addresses: phev@dtu.dk (Pablo Hevia-Koch), jala@kora.dk (Jacob Ladenburg) 
Energy Package, have been more and more focused on developing energy projects that do not depend on fossil fuels. In this context, wind energy has shown to be a clean technology with great potential for fulfilling these goals.

Originally, wind projects were few and had the possibility of being located on areas where the sites would not impact population centres and/or recreational areas. Currently, due to the significant growth that wind energy has experienced, some of the disamenities from wind turbine siting are being experienced more often by the population, namely visual impacts and noise disturbances (Gibbons, 2015; Jensen et al., 2014; Ladenburg and Lutzeyer, 2012; Sunak and Madlener, 2016). The perceived disamenities associated with wind power development have reached a level where some wind turbine projects have been terminated and scrapped due to resistance from the public arising from these disamenities.

This situation presents a tough decision making environment for the selection of wind turbine sites. While the public resistance due to disamenities is minimised when moving the wind turbines further away from population centres or even offshore, the costs of doing so increase considerably, especially when deciding to make the transition towards offshore wind turbine sites (EEA, 2009; Energistyrelsen, 2014). Accordingly, the choice of developing at different sites becomes an economic trade-off decision between costs of energy and external costs of the wind turbines projects.

As a consequence, the necessity for the measurement of external costs arising from the visual impact of new projects is evident. Quantification of the external costs can provide policy makers with important information when considering the trade-off between the technical advantages of the particular site, and the disamenities created.

Responding to this need, a large number of studies applying stated preference economic valuation methods have emerged the past 10-15 years. Most of these studies have estimated preferences for visual impact reduction either directly as a function of distance/number of turbines/formation of wind farms; or indirectly as a function of the location of the wind turbines. Interestingly, as we will discuss and argue in this paper, $31 \%$ of the 26 studies considered do not use visualisations at all, and $44 \%$ only use simple visualisations and thus depend on the cognitive ability of the respondent to create images showing the visual impact in their mind. Accordingly, it seems fair to question whether these economic valuation studies might fail to give reliable and objective information about the visual impacts attributes in focus, by the means of visualisations.

The aim of the present paper is to put economic valuation of visual impacts from wind turbines into an economic model framework, and based on this, to discuss and derive arguments for why rigorous visual aids are a necessary tool for eliciting valid and trustworthy answers from respondents in stated preference surveys. Accordingly, this paper also introduces a framework for classifying different existing visualisation approaches and applies it to give an overview of their use in recent studies. First, the importance of visualisations is derived from the economic model of perceived preferences presented by Blomquist and Whitehead 
(1998) considering the relevance of the visualisation presentation method itself, the attributes included in it, and the potential prior information people might have about the resource quality changes caused by wind power development. This is followed by a discussion of the possibility of respondents not having correctly updated priors, stressing out the use of visualisations. Afterwards, a framework for classifying visualisation approaches is presented, highlighting benefits and weaknesses of each method. Finally, a selection of recent studies regarding wind turbine valuation is classified utilising the presented framework and recommendations and conclusions are given.

\section{An economic model for visual resource quality changes}

\subsection{Economic model of perceived quality}

Following Blomquist and Whitehead (1998), for a representative agent, the perceived quality $q$ of a good can be expressed in terms of the actual quality of the good $\theta$, and the information received during the survey regarding the good's quality $I$ :

$$
q=\overbrace{\beta \cdot \theta}^{\text {Prior Info. }}+\overbrace{\delta \cdot I}^{\text {Add. Info. }}
$$

Both the actual quality of the good and the information received during the survey are subject to individual learning parameters $\beta$ and $\delta$, respectively. These learning parameters do not refer to the amount of information provided, but to the capability of the respondent for absorbing this information, either due to personal characteristics (Cerda et al., 2014), motivation for processing the information (Meyers-Levy, 1986), the relevance of the information (Ertac, 2011), the availability of the information (Hoehn and Randall, 2002; Ladenburg et al., 2014), differences in prior information (Ladenburg et al., 2014; Tkac, 1998), or the type/quality of the information medium chosen (Bateman and Mawby, 2004; Blomquist and Whitehead, 1998; Cerda et al., 2014; Hoehn and Randall, 2002; Jacobsen and Boiesen, 2008; Hevia-Koch and Ladenburg, 2015). Therefore, the term $\beta \cdot \theta$ expresses the total amount of prior information on the resource quality that the respondent has regarding the good, while the term $\delta \cdot I$ represents the total effect on the perception of the resource quality from the information added to the respondent during the survey. ${ }^{1}$

Expanding this formulation from the standard CVM study framework used in Blomquist and Whitehead (1998) to the standard set-up of a Choice Experiment including $n$ resource quality attributes of the good in focus, it is important to note that the quality changes under evaluation depend on the values of the $n$ attributes and therefore the terms of eq. (1) can be expressed as vectors:

\footnotetext{
${ }^{1}$ It is important to note that this simple model does not exclude dynamic learning parameters allowing for value and institutional learning, as in Braga and Starmer (2005) or Bayesian preference updating processes as shown in Israel (2005). However, it is beyond the scope of the present article to expand the model while considering these dynamics.
} 


$$
\begin{aligned}
q & =\boldsymbol{\beta} \cdot \boldsymbol{\theta}+\boldsymbol{\delta} \cdot \boldsymbol{I} \\
& =\left[\beta_{1}, \ldots, \beta_{n}\right] \cdot\left[\theta_{1}, \ldots, \theta_{n}\right]+\left[\delta_{1}, \ldots, \delta_{n}\right] \cdot\left[I_{1}, \ldots, I_{n}\right]
\end{aligned}
$$

Where every term of the vectors $\boldsymbol{\theta}$ and $\boldsymbol{I}$ represent the actual quality change produced by a specific attribute of the good, and the information given to the respondent regarding that particular attribute of the good during the survey, respectively. In the same way it is possible, if desired, to further expand the individual learning parameters for actual quality and given information, to a "per-attribute" basis, shown here as $\boldsymbol{\beta}$ and $\boldsymbol{\delta}$. This can be used to express that some information is given in the survey using different mediums, such as text or images, which have different communication qualities and information absorption rates Bateman et al. (2002), shown in the per attribute values of $\boldsymbol{\delta}$. In the same way, while some attributes of a good might be well known by the general population, other attributes might be more ambiguous or subject higher levels of lack of knowledge or even misinformation, being reflected in the per attribute values of $\boldsymbol{\beta}$.

If we look at past wind power preference studies (Álvarez-Farizo and Hanley, 2002; Dimitropoulos and Kontoleon, 2009; Ek, 2006; Krueger et al., 2011; Ladenburg and Dubgaard, 2007; Landry et al., 2012; Meyerhoff et al., 2010; Navrud and Bråten, 2007; Westerberg et al., 2013), preferences regarding visual disamenities produced by wind turbines are driven by many different attributes of the wind turbine farm: number of turbines $N$, size of each individual turbine $S$, grouping of the turbines in the farm $G$, distance of the turbines from the viewpoint $D$, features of the particular landscape $F$, location of the turbines in the landscape $L$, just to mention some. Therefore, expanding eq. (2) for the particularities of wind turbine visual disamenities yields:

$$
\begin{aligned}
q= & {\left[\beta_{N}, \beta_{S}, \beta_{G}, \beta_{D}, \beta_{F}, \beta_{L}\right] } \\
& \cdot\left[\theta_{N}, \theta_{S}, \theta_{G}, \theta_{D}, \theta_{F}, \theta_{L}\right] \\
+ & {\left[\delta_{N}, \delta_{S}, \delta_{G}, \delta_{D}, \delta_{F}, \delta_{L}\right] } \\
& \cdot\left[I_{N}, I_{S}, I_{G}, I_{D}, I_{F}, I_{L}\right]
\end{aligned}
$$

Based on this expansion it is possible to extract some meaningful observations regarding the importance of the survey design. As researchers, we are interested in obtaining preferences from respondents that are adequately informed about the consequences of the resource quality changes. As shown in eq. (3) this information has two sources: prior information possessed by the respondents, and the information given during the survey related to the specific attributes. Focusing on the latter, it must be the goal of the information given in the survey to update the prior information people have about the good in focus so they can state valid preferences for the resource quality changes. However, this might not be necessary 
if the respondents have sufficient levels of prior information. On the other hand, if we suspect that the respondents do not hold sufficient levels of prior information, we need to make sure to correctly update this prior information, and make a decision of what kind of visualisations to use. In the following section we will elaborate on the expected level of prior information among respondents in stated preference surveys eliciting preferences for wind power development. This is followed by and introduction to the different types of visualisations available and a review of how they have been used in academia.

\subsection{Do we need to update preferences?}

Looking at the complexity of eq. (3) naturally raises the question of whether we need to apply visualisations, and whether it is worth the effort to generate visualisations that objectively and accurately represent the changes in the visual landscape amenities. Two elements should influence this decision: do the respondents hold sufficiently high levels of prior information, and what is the impact of the visualisations on their expected stated preferences?

If we start with the former, we generally cannot expect all respondents in stated preference studies to have perfect knowledge about the good in focus. This is supported by studies that assess the level of prior information in respondents. Hoehn and Randall (2002) test different types of information on respondents of stated injury severity index related to a contingent valuation study, and find that heterogeneous effects from prior and new information exist. By assessing the level of prior information in a study focusing on preferences for wetlands, Czajkowski et al. (2014) find, based on nine questions related to the respondents prior information, that only $2.2 \%$ of the respondents can be characterized as having a high level of prior information and as many as $59.1 \%$ have a low level of information. In LaRiviere et al. (2014) the mean level of 8 questions probing for prior knowledge is 6 in a Choice Experiment on preferences for cold water coral reefs. In a third study examining preferences for river restoration (Kataria et al., 2012) it can be seen that approximately $34 \%$ of the respondents find that the river quality of the status-quo situation was different than the one presented in the scenario description.

If we move on and look into studies with a focus on wind power, the level of specific experiences with wind turbines has typically been assessed by asking respondents about the type and amount of experience they have with wind turbines. In Krueger et al. (2011) the share of respondents who have seen a wind turbine during their lifetime ranges between $54.3 \%$ to $72.9 \%$ across three samples. In two different Danish surveys (Ladenburg et al., 2013; Ladenburg, 2014) between $4.9 \%$ to as much as $64.4 \%$ of respondents have an onshore wind turbine in the viewshed from their permanent residence or summerhouse and $4.6 \%$ to $21.5 \%$ have an offshore wind turbine in the viewshed. Finally, while $23.6 \%$ report to see every day between 0 to 5 turbines, $27.2 \%$ see 6 or more turbines on a daily basis.

From the previous results, it can be seen that in the Danish case the existence of certain prior experience with wind turbines seems evident. However, even though respondents might be relatively well informed in 
regard to onshore wind turbines, the need for updating their knowledge through visualisations might still be relevant. For example, let us say that a study regarding wind turbine farms includes 3 dimensions: two types of grouping (groups of 10 and 20 turbines), two types of wind turbine sizes (1 [MW] and $2[\mathrm{MW}]$ ) and two distances from the specific view point under study $(0.5[\mathrm{~km}]$ and $1[\mathrm{~km}])$. This is equal to $2 \cdot 2 \cdot 2=8$ different possible scenarios of quality changes in the landscape amenities. If the respondents only have experience with one or few of those visual dimensions, (groups of 10 turbines of 2 [MW] size each at a distance of 0.5 $[\mathrm{km}]$ ), then if not presented with any visualisations, they have to create their own imagined impression of the quality changes in the landscape amenities in the 7 attribute combinations based on single experience combination. Another way to illustrate these properties is to use the offshore wind farm preferences data from Ladenburg and Dubgaard (2007) and Ladenburg et al. (2011). When the studies were carried out, several offshore wind farms were in operation with varying number of turbines in the wind farms $\theta_{N}[\mathrm{~m}]$, size of turbines, $\theta_{S}$, and distances from the shore, $\theta_{D}[\mathrm{~km}]$. Therefore, for this case previous information with the particular values existing at the time can be represented as:

$$
\boldsymbol{\beta} \cdot\left[\theta_{N}\left(\begin{array}{c}
3 \\
8 \\
10 \\
11 \\
20 \\
72 \\
80
\end{array}\right), \theta_{S}\left(\begin{array}{c}
53.5 \\
64.5 \\
102 \\
103.5 \\
110 \\
158 \\
161.2 \\
163.8 \\
170
\end{array}\right), \theta_{D}\left(\begin{array}{c}
0 \\
2 \\
2.5 \\
3 \\
6 \\
14
\end{array}\right)\right]
$$

However, the scenario description stipulated the use of 5 [MW] turbines in wind farm sizes of 49, 100 and either 144 turbines (Ladenburg and Dubgaard, 2007) or 100 turbines (Ladenburg et al., 2011); at 8, 12 18 and $50[\mathrm{~km}]$ from the shore:

$$
\left[\delta_{N}, \delta_{S}, \delta_{D}\right] \cdot\left[I_{N}\left(\begin{array}{c}
49 \\
100 \\
144
\end{array}\right), I_{S}(160), I_{D}\left(\begin{array}{c}
8 \\
12 \\
18 \\
50
\end{array}\right)\right]
$$

Though there exists some overlap in the attribute levels, particularly regarding the size of the wind turbines, for both remaining attributes there is a non-trivial difference on the levels existing as part of prior information in comparison to the levels considered on the scenario description: The number of turbines in the existing wind farms is generally lower compared to the levels in the scenario description, and the distances 
considered are quite larger than most of the existing distances. We can see that in this case, even if the respondents did have previous information related to wind farm developments; this previous information was based on wind turbines with dissimilar characteristics to the ones considered in the scenario of the study. Because these differences reside on attributes that have a significant influence on the visual impact produced by the wind farms, they introduce a considerable distortion on the estimation of visual disamenities reduction preferences.

The case becomes even more evident if we look into some of the other offshore wind power studies. Several offshore wind power preferences studies have been carried out among population groups which we cannot expect respondents to have any specific prior information about the resource quality changes caused by the visual attributes of offshore wind power. Let us look at Koundouri et al. (2009); Krueger et al. (2011); Landry et al. (2012); Westerberg et al. (2013); Vecchiato (2014): To the authors best knowledge, when these studies were carried out no offshore wind farms were in operation neither in US, Greek, Italian nor French waters. In these studies, the primary offshore wind turbine attribute is the distance from the coast for fixed wind farm and turbine sizes within each study i.e. $\theta_{D}$ and $I_{D}$. Accordingly, the level of prior information related to the quality change of the landscape amenities from offshore wind farms was extremely low $^{2}$, i.e:

$$
\boldsymbol{\beta} \cdot\left[\theta_{N}, \theta_{S}, \theta_{D}\right] \approx 0
$$

However, the scenario description stipulated the use of wind turbines of varying sizes $\theta_{S}[\mathrm{~m}]$, number of turbines in the wind farms, $\theta_{N}$, and distances from the shore, $\theta_{D}[\mathrm{~km}]$ :

Vecchiato (2014):

$$
\left[\delta_{N}, \delta_{S}, \delta_{D}\right] \cdot\left[I_{N}\left(\begin{array}{c}
4 \\
15 \\
50
\end{array}\right), I_{S}\left(\begin{array}{c}
450 \\
120 \\
200
\end{array}\right), I_{D}\left(\begin{array}{c}
0.1 \\
0.25 \\
1
\end{array}\right)\right]
$$

Krueger et al. (2011):

$$
\left[\delta_{N}, \delta_{S}, \delta_{D}\right] \cdot\left[I_{N}(500), I_{S}(135), I_{D}\left(\begin{array}{c}
1.44 \\
5.76 \\
9.60 \\
14.40 \\
\text { Not Visible }
\end{array}\right)\right]
$$

Landry et al. (2012):

\footnotetext{
${ }^{2}$ Naturally, the respondents might use prior knowledge related to other (non-wind power) coastal landscape features in the evaluation of the change in the seascape quality caused by wind farms at different distances. However, as a researcher/analyst we should have an idea of which elements might affect the respondents assessment and control for them if possible.
} 


$$
\left[\delta_{N}, \delta_{S}, \delta_{D}\right] \cdot\left[I_{N}(\mathrm{~N} / \mathrm{A}), I_{S}(130), I_{D}\left(\begin{array}{l}
1.6 \\
6.4
\end{array}\right)\right]
$$

Westerberg et al. (2013):

$$
\left[\delta_{N}, \delta_{S}, \delta_{D}\right] \cdot\left[I_{N}(30), I_{S}(135.5), I_{D}\left(\begin{array}{c}
5 \\
8 \\
12
\end{array}\right)\right]
$$

If a respondent has limited availability of prior information, or even no prior information at all, to assist in the value formation for a resource quality degradation caused by offshore wind turbines, the stated level of preferences can be expected to be strongly dependent on what kind information that the respondents are presented with during the survey:

$$
q \approx\left[\delta_{N}, \delta_{S}, \delta_{D}\right] \cdot\left[I_{N}, I_{S}, I_{D}\right]
$$

Clearly the choice of visualisation, and the quality thereof, can be expected to influence the value formation and the subsequent levels of WTP. This exemplifies the need for correctly updating respondents' information even in cases where there exists some prior information on the topic, due to possible discrepancies on the number and levels of the goods' attributes. Therefore, the challenge is to create a study design that allows us to compensate for the imperfect prior information held by respondents and thus obtain preference estimates that are based on the best possible measures of the perceptions in the resource quality change.

The role of visualisations becomes even more evident if a SP study aims at estimating preferences for dynamic attributes of wind turbines, such as shadow effects/flickering and night time illumination.

Shadow effects refer to the visual impact produced by the shadows cast by the wind turbines depending on the time of the day. As the sun moves across the sky, the size and location of this shadow changes, sometimes shadowing areas of interest. Particularly important is how the wind turbines shadow is cast during sunrise and sunset, as it is during those points in time that the shadow cast is the longest and has a bigger chance of impacting its surroundings. The rotation of the blades is also an important element to consider, as the shadows cast are not static, but will move across the surface several times per minute as the blades rotate. The effect of the moving shadows produced by wind turbines has been studied in Pohl et al. (1999), concluding that it has a noticeably disturbing effect in most people, that in some cases might surpass the visual disamenities arising from the wind turbine itself.

Regarding night time illumination, wind turbines tend to be illuminated for security reasons after sunset, and as a consequence their visual impact varies drastically in comparison to daytime conditions as the lights contrasting the dark background can be more eye-catching than the wind turbines themselves during daytime. As shown in Lutzeyer (2013), the preferences of respondents that are presented with daytime and 
night time visualisations are significantly different than the ones of respondents presented with only the daytime visualisation. In particular, day time only visualisation respondents present a lower disutility from visual impact than the respondents that were presented with both kinds of visualisation.

So jointly, in order to capture the visual resource quality degradation caused by wind turbines, we need to make clever choices that give the respondents the best tools possible to state valid and trustworthy preferences, being in line with the recommendations presented by previous ground literature such as Bateman et al. (2002); Arrow and Solow (1993); Champ et al. (2012); Carson and Mitchell (1989), where it is asserted that to be able to accurately assess the perception of a good, it is necessary to describe the attributes of the good under investigation in a way that is meaningful and understandable to respondents. It is important to emphasise the need for the descriptions to be not only correct and complete, but in particular meaningful and understandable, therefore "descriptions may require a combination of textual information, photographs, drawings, maps, charts and graphs" Bateman et al. (2002). This is particularly important if the respondents are asked to make choices among complex choice sets. In the field of cognitive and educational psychology, Carlson et al. (2003) find that performance improved if information was conveyed with diagrams and not text alone. Interestingly, this effect was only present in tasks involving higher levels of complexity. In Hoehn et al. (2010) two scenario information formats are tested: text only, and text including tabular data. The results suggest that the tabular format reduced the variance of the estimated preferences parameters and induced a lesser use of choice heuristics. Furthermore, Hevia-Koch and Ladenburg (2015) find that the screen size in web surveys influences the visibility and the details in visualisations and stated preferences.

However, as addressed by Arrow and Solow (1993); Boyle (2003), using photographs and visualisations of other kinds (such as video material, maps or interactive features) should be done with care:

"One effective mean for conveying information and holding interest in a CV interview has been the use of large and impressive photographs. However, this technique is a two-edged sword because the dramatic nature of a photograph may have much more emotional impact than the rest of the questionnaire. Thus it is important that photographs be subjected to even more careful assessment than verbal material if the goal is to avoid bias in presentation." - (Arrow and Solow, 1993, p55.)

Though the focus of the previous is on making sure that the respondents do not overestimate the value of the pictures shown as visualisations, the issue remains the same - visualisations of the changes in the resource quality can be powerful tools to increase the level of information among respondents, but due to the potential of generating distortion in the perceived values, it is paramount that their application is done in a rigorous manner. 


\section{The Visualisation Ladder and Review}

In this section we will present and discuss the different existing visualisation approaches in an incremental way, hereafter named the visualisation ladder, and review the use of different visualisations in academic literature. Some studies have used a mix of different types of visualisations while other studies have used one type of visualisation only. Furthermore, when we move on to analysing the studies using some kind of visualisation, it is important to discuss whether or not the visualisations are scaled relative to the attribute and attribute level in focus. For example if the visual attributes are five $3 \mathrm{MW}$ turbines (size) located 1 $\mathrm{km}$ from a view point (distance) the visualisations should represent both of those attributes in an accurate proportion. In the same line, if for example visualisations are used to give an impression of wind turbines in different landscapes, the wind turbines should be scaled identically, so that the distance to the turbines and number of size and the turbines are the same. If the visualisations are not scaled, the visualisations will give the respondents incoherent and potentially misleading information relative to the text description - being the point made by Arrow and Solow (1993).

\subsection{No Visualisations}

As a ground level, we have the no visualisation approach, where respondents are presented with textual information regarding the visual impact of the wind turbines but without any kind of visual aid. This approach has been widely used in previous studies, particularly because of its ease of implementation and evident inexpensiveness.

Among the 26 studies considered on the present paper, nine have decided not to present any visualisations to the respondents, and two have one or more visual attributes described by text only. Though these studies do not use visualisations, they still aim to estimate preferences for visual impacts attributes. Except for three (Navrud and Bråten, 2007; Börger et al., 2015; Georgiou and Areal, 2015), all of the studies include more than one visual attribute. Based on the model for preferences shown in eqs. (1) to (3), not giving any kind of visual aid stresses the dependence on the respondents prior experience with wind turbines/wind farms. In particular, when using only text for giving information on the scenario description, the learning factor $\delta$ will only relate to the changes described in words and it is up to the cognitive ability of the respondent to translate the written visual attribute changes into visual images based on his or her own skills, as well as the prior experience the respondent might have. This might be relatively easy when the study only includes one visual attribute, as done in Navrud and Bråten (2007); Börger et al. (2015); Georgiou and Areal (2015). However, when the studies include more than one visual attribute, the cognitive burden increases substantially, as the respondents are asked to trade-off visual impacts in multiple dimensions.

The best example thereof is the survey utilised in Meyerhoff et al. (2010). Without going into specific details, the respondents are asked to make choices between three onshore alternatives, that vary with the 
size of the wind farm (4-6 turbines, 10-12 turbine and 16-18 turbines), height of the turbines (110m, 150m and $200 \mathrm{~m})$ and distance from a residential area $(750 \mathrm{~m}, 1100 \mathrm{~m}$ and $1500 \mathrm{~m})$. Accordingly, the respondents state their preferences for wind power development including $3 \cdot 3 \cdot 3=27$ different visual outlays. Though the study is carried out in Germany, which has one of the highest wind power capacities in world, and the respondents might have some experience with onshore wind power, the task of accurately trading off the visual attributes without any visual reference for all of these dimensions in each scenario might be a serious cognitive challenge.

Another example can be seen in Campbell et al. (2011). This study estimates preferences for locating wind farms of three sizes (300, 500, and 800 football pitches), in different locations (offshore, onshore, on coast and in the mountains). The study was conducted in Chile, and at the time the study was carried out, there were no offshore wind farms in Chile, and a very limited amount of onshore wind farms. Accordingly, it can be expected that the respondents might have very weak prior information related to the visual attributes of an offshore wind farm and it might therefore be more difficult for the respondents to assess the type of visual impacts caused by offshore wind farms with the three different proposed sizes. In the same line, but considering only a single visual attribute dimension, Georgiou and Areal (2015) elicit preferences for an offshore wind farm located $2.75 \mathrm{~km}$ and $4.1 \mathrm{~km}$ away from two Greek islands. In the study, respondents are indirectly asked to trade-off renewable energy development and the impact associated with offshore wind farms. However, despite the potential visual impacts, the survey does not give any kind of visual aids (and does not mention the dimensions of the wind farms). Though several sites have been proposed for offshore wind power development (4COffshore, 2016), no offshore wind farms were in operation in Greek waters at the time the study was carried out. Accordingly, the respondents have little prior experience, which they can rely on.

The issue that we wish to raise is that the validity of the studies estimating the welfare cost of visual attribute disamenities from offshore wind farms without giving people visualisations could be questionable. That might be event if the respondents have some level of prior experience, This issue is acknowledged by Meyerhoff et al. (2010), that states on its conclusions section: "[...] as no visualisation was used interviewees could have misjudged the impact of high turbines on the landscape."

Due to these qualities, we would argue that the no visualisation approach should not be recommended for use in stated preference studies focusing on visual attributes of wind farms. An exception could be, if the respondents state preferences for removing the visual attribute impacts from a specific existing wind farms. In that case, we might expect that respondents have the visual impacts at first hand and therefore have good priors to state fair and just preferences. Due to the fact that visual impacts have been shown to be significant drivers for the preferences regarding wind turbines in both economic (Krueger et al., 2011; Ladenburg and Dubgaard, 2007; Landry et al., 2012); and non-economic studies (Betakova et al., 2015; Maehr et al., 2015; Palmer, 2015), it is important not to ignore the potential impact that these dimensions 


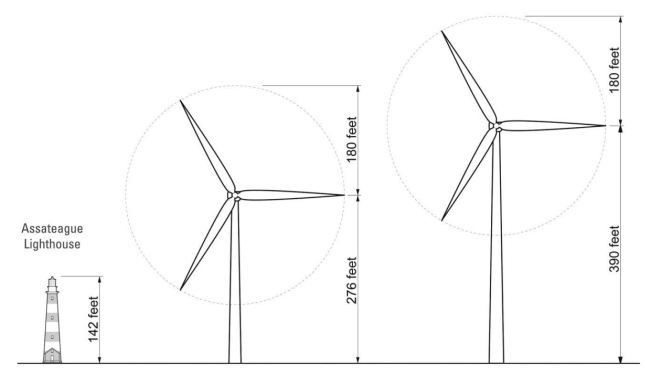

Figure 1: Relative visualisations from Boatwright (2013)

might produce when creating surveys that elicit preferences for wind energy.

\subsection{Relative Wind Turbine Size Visualisation}

This is the most basic approach to visualisations, where the respondent is shown only a diagram of the shape of the turbine, as well as the dimensions of it. It can also show some other form of reference, for example a human figure or a possible known building, next to the turbine. This type of visualisation has been utilised mainly due to its simplicity, as it does not require the creation of specific computer generated images or photographs, and represents an incremental step forward from the no visualisation approach.

From the studies reviewed, there are only two that decided to use relative visualisations. In Boatwright (2013), relative visualisations are utilised to present the size of two different types of wind turbines, an example of which is shown in fig. 1. The turbines are shown relative to a specific lighthouse, relating the scale of the turbines to a possibly known landmark. Importantly, the relative sizes shown have the same ratios as the numbers put forward in the relative visualisations, that is, the images of the wind turbines are scaled correctly according to their stated sizes. Thus, the respondent gets a true picture of the relative differences from the visualisations.

Another study (Vecchiato, 2014) utilises relative visualisations for representing three different dimensions: size of the wind turbines, distance from houses, and number of turbines in the farm. Unfortunately, the visualisations used suffer from scaling problems that hinder their quality and usability. Though there is some information about the differences in the visual attributes, much of it is left up for the respondents to cognitively process, and even worse, is distorted by images where their visual aspect does not match the stated distances, sizes and numbers.

If we go into more detail, it can be seen that the ratios of the wind turbine sizes are approximately 1:1.67:2.33 in the relative visualisations, but 1:2.4:4 in the text description of the scenario. The same problem seems to be the case with the wind farm sizes. In the relative visualisations, the wind farms size ratios are 3:7:11, which should be compared to 4:15:50 in the text. The relative visualisations related to the distance of the wind turbine to housing areas is also highly questionable, though verification requires 


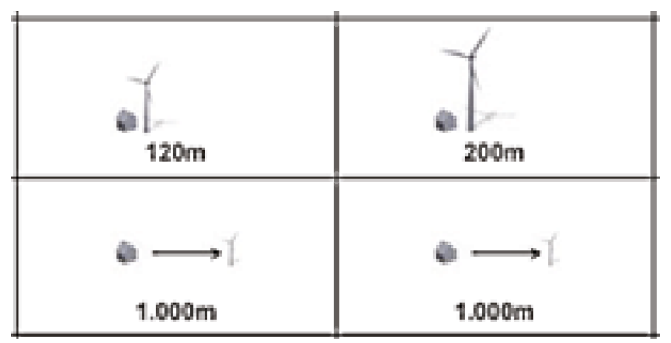

Figure 2: Relative visualisations from Vecchiato (2014)

access to a wind visualisation program. First, it can be seen that the distance itself between the house and the turbine is incorrectly scaled. Secondly, it can be seen that as the wind turbine is drawn further away from the house, its size is changed, perhaps to illustrate the changing effect on how visible it is from the house. It seems, that this scaling effect shown on the image is not based on the actual change of apparent size depending on distance, but merely introduced in an arbitrary amount. All of these effects can be seen on fig. 2 .

Overall, the use of relative visualisations gives some information to the respondents, but still offloads the burden of determining the actual visual impact onto them. As such, we might expected that there will be distortions regarding preferences for the distance and/or height for the wind turbines, as the respondents answers will be mostly based on what they think the visual impact will be and not on the actual impact. Particularly evident in the case of the distance attribute, where the relative visualisation helps understand how far away from viewpoint the turbines will be located, but does not give information regarding the visual effect of that movement.

That said, these kinds of visualisations will be an improvement from no visualisation at all when respondents have never seen a wind turbine before and therefore have no reference point at all. If respondents have prior experience with wind turbines, the effectiveness of this visualisation approach is debatable. While this approach presents an improvement on the relevance of the $I$ factor of the economic model, it is not enough to present a reasonable amount of information relevant for the decision making process of the respondents, particularly if the amount of experience they have with wind turbine is close to non-existent.

\subsection{Generic Visualisation}

In this kind of visualisation the wind turbines are shown in a generic environment, and scaled according to the turbine characteristics, and distance. This is normally done by utilising computer generated images that combine or generate a geographical location and insert the wind turbine in it, correctly scaled and illuminated.

This approach proves much better than the two previous ones as it does not require the respondent to imagine the effect of changing the turbine's height or distance, instead showing it explicitly. In this 


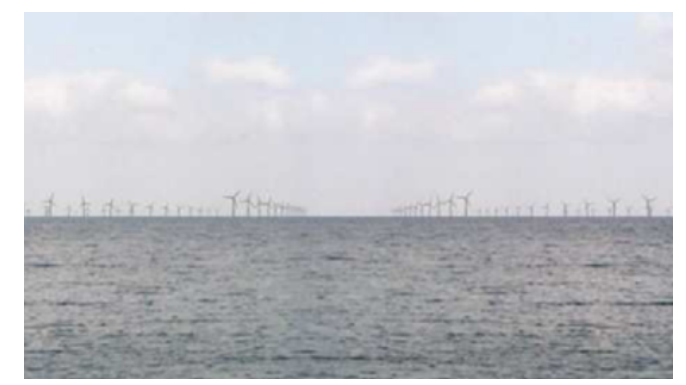

Figure 3: Generic offshore visualisation from Ladenburg and Dubgaard (2007) (cropped)

manner, the effects of the proposed alternatives are much clearer. This is the simplest approach that is capable of presenting actual visual impact changes to the respondents. As seen on the previous sections, it is possible to include various dimensions of attributes on the visualisation, as for example grouping, size, distance and number of turbines. Two important advantages are that its simplicity is reflected on ease of creation and lower cost; and the fact that by being generic it can be applied when referring to scenarios with indeterminate location or when doing cost-benefit analysis that has to be applied to a numerous amount of scenarios, making site-specificity infeasible.

Seven of the reviewed studies use generic visualisations to present all visual attributes and three studies to present at least one of the visual attributes, an example of which can be found in fig. 3. However, as we will come back to, the scale of the applied visualisations and the comparability across visualisations is questionable in some of the reviewed studies.

If we start with the former, Ek (2006); Vecchiato (2014); Hosking et al. (2013); Strazzera et al. (2012) all use generic visualisations that are out of scale. In Ek (2006), the wind turbines located onshore, offshore and in the mountains seems to have different sizes and are visualized from different distances. The same issue is apparent in Vecchiato (2014) and as a consequence, the visualisations convey information that is not part of the visual attribute. In this study, for example, the wind turbines offshore can hardly be seen, which might make respondent prefer offshore locations to a higher extent, compared to had the turbines in the different landscape been equally scaled. In Hosking et al. (2013), the landscape type varies when presenting different wind farm sizes and the distance to the wind turbines from the nearest residential area. Accordingly, it is in principle impossible to decouple preferences for size and distance from the different landscapes that they are visualized in. Another study, by Strazzera et al. (2012), presents the same problem regarding strange scaling of wind turbine sizes on their provided visualisations. Unfortunately, as the study does not state which are the characteristics of the wind turbines used as a reference, it is not possible to accurately confirm if the apparent size of the wind turbines in the visualisations is correct.

Strazzera et al. (2012) also uses non-scientific generic visualisations to represent the potential visual impacts associated with locating wind turbines "close" and "far from" an unspecified archaeological site, 


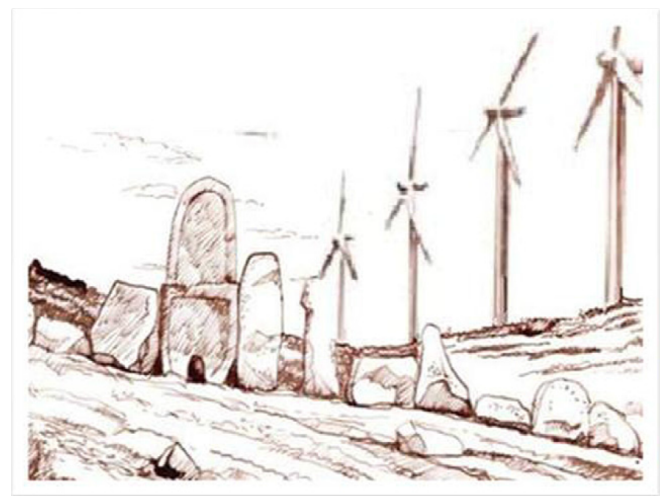

Figure 4: Non-scientific visualisation from Strazzera et al. (2012)

with hand drawn images. Though the wind turbines differ in size at the two visualisations, much is left for the respondents to imagine - particularly as one visualisation shows four turbines and the other five turbines. Though it is not possible to determine with complete certainty, it raises the concern that the visualisations are not correctly scaled and located, and therefore do not give an objective impression of the visual impacts. The same situation can be seen in the site specific visualisations, in which the turbines seem oddly large in the landscape (see fig. 4) and with varying numbers of turbines depending on the distance.

That said, in the remaining studies using generic visualisation, the turbines are correctly scaled, with a minor issue present in the study done by Teklay Abay (2014) where there seems be some scale differences between the onshore visualisations (in which all visual attributes are in scale) and offshore visualisations. Interestingly, most studies using generalized visualisations elicit preferences for offshore wind farms - two exceptions being Ackermann (2014); Teklay Abay (2014).

The main shortcoming of the generic visualisation approach comes from the fact that it does not take into account the particularities of the environment where the turbine might be located, as well as the turbines' specific location, which can have a big impact on the perceived quality change. A wind turbine situated in a large plain with no other geographic features on sight will probably be more visible than a wind turbine located behind a forest or hidden by hills. As such, this kind of visualisation might over- or under-represent the visual impact of the wind turbine due to specific particularities of the selected wind turbine site.

Another disadvantage compared to the relative wind turbine size visualisation is that it is significantly more time consuming to be done, as it will be based on computer generated images that have to correctly account for wind turbine height and distance.

\subsection{Site-Specific Visualisation}

A site-specific visualisation not only accounts for the differences in distance and size of the wind turbines, as the generic visualisation does, but also shows the turbines immersed in the relevant geographical location. This allows the respondents to observe how the proposed project would look in the particular siting location, 


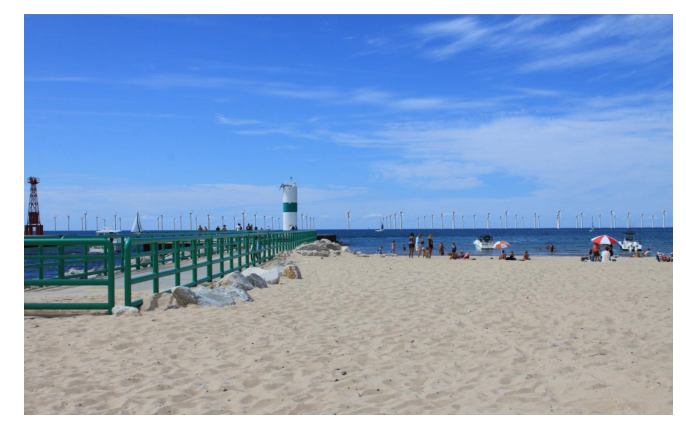

Figure 5: Site-specific visualisation from Knapp et al. (2013)

which can have a serious effect on the perception of the visual impact. Out of the reviewed studies, four utilise site-specific visualisations for presenting the visual attributes of the scenario. An example is shown in fig. 5

As wind turbine farms can be placed in locations of very different aspects and geographies, the visual impact associated to them can vary notably even when the turbine size and distance is the same. Turbines hidden by hills or a forest are evidently going to be less visible than if they were located on an open field. On the other hand, turbines that obstruct or distract from the view of an historical building, or a pleasant geographical landmark, will be considered having a bigger impact even if the size and distance do not change. This effect is more evident in places that have a value linked to its visual condition, as happens in areas where there are relevant tourism and recreational activities, or areas of particular historical or natural significance. Site-specific visualisations are able to show this effect, and therefore clarify any possible misunderstandings regarding the particular nature of the project on the respondents' part. For this reason, it further refines the amount of information given to and absorbed by the respondent, due to increasing the quality of both the learning coefficient $\boldsymbol{\delta}$ and the information given $\boldsymbol{I}$.

Evidently, this adds another level of complexity to the creation of these visualisations, as the conditions for the creation of generic visualisations are maintained, but now with the added requirement of using images specific to the proposed wind turbine locations. If the number of locations under study is big, then the cost and complexity for commissioning the creation of these visualisations increases significantly.

This visualisation approach has the potential to introduce important improvements over the generic visualisations. It is recommended to utilise this approach on projects where there exists reasons for believing that the geographical setting might impact the extent and acceptance of the visual impacts.

\subsection{Dynamic Visualisation}

One of the main characteristics of wind turbines is the movement of their blades. It has been shown that human vision responds more to moving objects (Franconeri and Simons, 2003), and therefore when looking at a wind farm this movement might make the wind turbines much more noticeable than if they were fully 


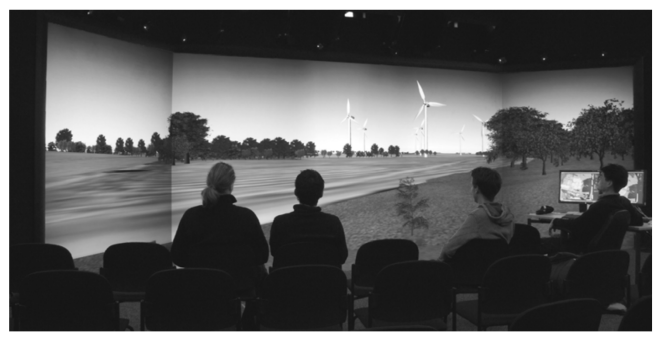

Figure 6: Site-specific visualisation from Zehner (2009)

static. For this reason, visualisations that only include still images are unable to fully capture the visual impact arising from the movement of the wind turbines' blades.

A dynamic visualisation is a visualisation that changes its appearance over time, and as such it can illustrate the effect of movement whether by utilising a recorded video or a computer generated one. While the movement of the wind turbines' blades is an obvious candidate for being shown on a dynamic visualisation, it is not the only attribute that might benefit from it. Another attribute that can be represented utilising a dynamic visualisation is the interaction between the wind turbine and the sun, where the moving shadows can have an impact much higher than just a static shadow cast by the turbine when the sun rises or sets behind it, as explained on Section 3. While showing a picture of the shadow of a turbine falling in a house might illustrate some level of discomfort, utilising a dynamic visualisation that shows the shadow sweeping across the house several times per minute may paint a more appropriate picture. Other elements that might be possible to show are weather conditions, time of the day, obstructing car traffic, and more.

Because of the definition of dynamic visualisation, it is not completely a separate visualisation type per se, but it can be applied to any of the previously shown visualisation types. For the reasons outlined on the previous sections, it is evident that the biggest benefit and the most accurate visualisation would be generic and site-specific dynamic visualisation, as they will capture most of the elements that accurately represent the visual impact of wind turbine farms.

While video images are a standard approach for dynamic visualisations, they are not the only solution. More advanced techniques could include generating a full virtual environment where it is possible to see the proposed wind turbines in the selected environment from different points of view, with varying weather and time of the day conditions. One example of this is the work done in Zehner (2009), where he utilises a projected virtual reality environment to create a visualisation that allows respondents to experience the visual impact of the wind turbines in a way as close as possible to real life, as shown in fig. 6 .

The shortcomings of dynamic visualisations are related mainly to the cost and complexity. Generating these visualisations is definitely a more time consuming process, as it is necessary to generate a video or even a full virtual environment, not only a picture. Another restriction is that a dynamic visualisation limits the possibility of utilising mailed or printed surveys, and makes the logistics of applying the survey more 
complicated. In this aspect, internet based surveys seem to gain an advantage due to the relative simplicity of including video material on an internet site. For more elaborate set-ups, like the virtual reality based one done by Zehner (2009), the survey must be applied in person on a prepared location, making the study much more expensive and challenging.

Despite these challenges, this kind of visualisation is what future studies should aim towards, as it allows for the best representation of the scenarios under study and for representing relevant elements largely ignored in current visualisations (shadows, lighting, weather, night illumination and blade movement).

\section{Assessment of Visualisation Methods on Literature}

In the presentation of the visualisation ladder, it is clear that the studies have used difference approaches to give the respondents information on the visual dimensions of wind power development. In the following section, we apply the visualisation ladder actively, and subjectively rate the different studies in terms of the specific visual attributes in the studies, as well as the ability of the studies to convey objective visual impact information. For each study, we list the amount of attributes under study whose preferences are related to the visual impacts produced by the wind turbines; and the visualisation approach used. The possible visual attributes considered are: Size of the wind farm, Height of the wind turbine, Location of the wind farm regarding terrain or specific geographical area, Distance to residential areas/relevant sites, and Visibility of the wind farm from residential areas/relevant sites.

Based on this, we have tried to assign a level of visual adequacy to each study, that represents how effective are the visualisations chosen at correctly characterising the visual impact of the attributes that the study considers. The adequacy is graded on a relative scale that ranges from 0 to 4 , with 0 being a very low level of visual adequacy, and 4 being the highest for the analysed studies. It is important to note that this assessment is only referred to visual aspect of the study, and is not an evaluation of the study quality as a whole.

From the results shown on Table 1 two issues can be observed. Firstly, there is a substantial number of studies that focus on visual attributes, while not providing any kind of visualisation that includes them. Secondly, many of these studies focus on several attributes that affect the visual impact at the same time while not providing an adequate representation of these attributes on the visualisation, nor choosing a relevant visualisation type. From our perspective, this can be seen in Hosking et al. (2013); Vecchiato (2014); Boatwright (2013); Meyerhoff et al. (2010). This is not to say that it is impossible to study several visual attributes at once: note that while Lutzeyer (2013) also considers many different attributes with relation to the visual impact, the visualisations chosen manage to give an objective representation of all of them, both due to the choice of creating site-specific visualisations, as well as the attributes included in them. 
Table 1: Literature Assessment

\begin{tabular}{|c|c|c|c|}
\hline Study & Visualisation and Attributes & Adequacy & Journal \\
\hline Ackermann (2014) & $\begin{array}{l}\text { Height: Generic and Scaled } \\
\text { Distance: Generic and Scaled } \\
\text { Size: Generic and Scaled }\end{array}$ & 1 & Master Thesis \\
\hline Álvarez-Farizo and Hanley (2002) & Location: Site-specific and Scaled & 4 & Energy Policy \\
\hline Boatwright (2013) & $\begin{array}{l}\text { Height: Relative and Scaled } \\
\text { Size: Generic and Scaled } \\
\text { Visibility: None }\end{array}$ & 1 & Master Thesis \\
\hline Börger et al. (2015) & Height: None & 1 & $\begin{array}{l}\text { Environmental } \\
\text { Science \& Policy }\end{array}$ \\
\hline Campbell et al. (2011) & $\begin{array}{l}\text { Size: None } \\
\text { Location: None }\end{array}$ & 0 & $\begin{array}{c}\text { Applied Economic } \\
\text { Letters }\end{array}$ \\
\hline Dimitropoulos and Kontoleon (2009) & $\begin{array}{l}\text { Height: None } \\
\text { Size: None }\end{array}$ & 0 & Energy Policy \\
\hline Ek and Persson (2014) & Location: Generic (No Turbines) & 2 & $\begin{array}{l}\text { Ecological } \\
\text { Economics }\end{array}$ \\
\hline Ek (2006) & $\begin{array}{l}\text { Height: None } \\
\text { Size:None } \\
\text { Location: None }\end{array}$ & 0 & Book Chapter \\
\hline Georgiou and Areal (2015) & Distance: None & 0 & $\begin{array}{c}\text { Renewable and } \\
\text { Sustainable } \\
\text { Reviews }\end{array}$ \\
\hline Hosking et al. (2013) & $\begin{array}{l}\text { Clustering: Generic Not Scaled } \\
\text { Distance: Generic not Scaled } \\
\text { Size: Generic not Scaled }\end{array}$ & 0 & Master Thesis \\
\hline
\end{tabular}


Table 1: Literature Assessment (cont.)

\begin{tabular}{|c|c|c|c|}
\hline Study & Visualisation and Attributes & Adequacy & Journal \\
\hline Knapp et al. (2013) & Distance: Site-specific and Scaled & 4 & Master Thesis \\
\hline Koundouri et al. (2009) & $\begin{array}{l}\text { Size: None } \\
\text { Visibility: None }\end{array}$ & 0 & Energy Policy \\
\hline Krueger et al. (2011) & $\begin{array}{l}\text { Distance: Generic and Scaled } \\
\text { Location: Generic and Scaled }\end{array}$ & 2 & Land Economics \\
\hline Ladenburg and Dubgaard (2007) & $\begin{array}{l}\text { Distance: Generic and Scaled } \\
\text { Size: Generic and Scaled }\end{array}$ & 3 & Energy Policy \\
\hline Ladenburg et al. (2011) & Distance: Generic and Scaled & 3 & $\begin{array}{l}\text { Danish Journal } \\
\text { of Economics }\end{array}$ \\
\hline Landry et al. (2012) & Distance: Site-specific and Scaled & 4 & $\begin{array}{l}\text { Resource and } \\
\text { Energy }\end{array}$ \\
\hline Lutzeyer (2013) & $\begin{array}{l}\text { Distance: Site-specific and Scaled } \\
\text { Size: Site-specific and Scaled } \\
\text { Visibility: Site-specific and Scaled }\end{array}$ & 4 & Ph.D. Thesis \\
\hline Meyerhoff et al. (2010) & $\begin{array}{l}\text { Height: None } \\
\text { Distance: None } \\
\text { Size: None }\end{array}$ & 0 & Energy Policy \\
\hline Mirasgedis et al. (2014) & Visual Impact: None & 0 & $\begin{array}{l}\text { Renewable and } \\
\text { Sustainable } \\
\text { Energy Reviews }\end{array}$ \\
\hline Navrud and Bråten (2007) & Size: None & 0 & $\begin{array}{l}\text { Revue d'Economie } \\
\text { Politique }\end{array}$ \\
\hline Reed and Scott (2014) & $\begin{array}{l}\text { Distance: None } \\
\text { Size: None }\end{array}$ & 0 & $\begin{array}{l}\text { Journal of Environmental } \\
\text { and Resource Economics }\end{array}$ \\
\hline Strazzera et al. (2012) & $\begin{array}{l}\text { Distance: Artistic Generic Not Scaled } \\
\text { Location: Artistic Generic Not Scaled }\end{array}$ & 1 & Energy Policy \\
\hline
\end{tabular}


Table 1: Literature Assessment (cont.)

\begin{tabular}{|c|c|c|c|}
\hline Study & Visualisation and Attributes & Adequacy & Journal \\
\hline Teklay Abay (2014) & $\begin{array}{l}\text { Height: Generic and Scaled } \\
\text { Distance: Generic and Scaled } \\
\text { Size: Generic and Scaled } \\
\text { Location: Generic and Scaled } \\
\text { within offshore/onshore }\end{array}$ & 3 & Master Thesis \\
\hline Vecchiato (2014) & $\begin{array}{l}\text { Height: Relative and Not Scaled } \\
\text { Distance: Relative and Not Scaled } \\
\text { Size: Relative and Not Scaled } \\
\text { Location: Generic and Not Scaled }\end{array}$ & 0 & Aestimum \\
\hline Westerberg et al. (2013) & Distance: Site-specific and Scaled & 4 & Tourism Management \\
\hline Zehner (2009) & $\begin{array}{l}\text { Height: Dynamic VR } \\
\text { Distance: Dynamic VR } \\
\text { Location: Dynamic VR }\end{array}$ & $-*$ & Conference Paper \\
\hline
\end{tabular}

* Zehner (2009) is not a valuation study but a demonstration of how to utilise VR visualisations for wind turbines' visual impact valuation. 
The relevance of any study that wants to address the economic significance of visual impacts, is directly associated to the scientific rigour with which the scenario description, and associated visualisations, are created. From this perspective, carrying out a study that focuses on a elevated number of visual attributes without the necessary quality of the scenario description, does not yield solid scientific conclusions and gives less grounds for application in policy decisions and economic analysis. Because of this, if researchers are faced with resource and/or time constraints that make it infeasible to create high quality visualisations for all visual attributes under study, limiting the amount of these attributes while making sure that the remaining ones are correctly represented in the scenario description, will allow them obtain conclusions of much higher scientific value.

\section{Conclusions}

While the topic of visual impacts for wind generation has been increasingly discussed on recent literature, the importance of including visualisations as a central part of the scenario description has not yet been discussed in depth. Considering the relevance of valuation in policy making, and the increasing deployment of wind energy on a global scale, it is necessary to make use of better methods and studies for estimating the value of visual disamenities produced by wind turbines.

By extending the theoretical model for perceived quality done by Blomquist and Whitehead (1998), this paper presents arguments towards the necessity of visualisations as part of the standard scenario description on any study whose conclusions might be influenced by the effects of visual impact of wind turbines. In particular, the importance of both the presentation of the visualisation, the scaling of the visual attributes, as well as the attributes of the wind turbine scenario represented on it, might influence the perceived quality of the good by respondents.

We develop and present the visualisation ladder, a framework for classifying different visualisations approaches, which allows us to have a starting point for comparing visualisation techniques in regard to the presentation method chosen, and to be able to discuss decisions made in recent studies in a comparative manner. The visualisation ladder also presents alternatives to current researchers regarding possibilities for visualisation of the visual impact for wind turbines, while highlighting their general benefits and shortcomings. It also makes it possible to comparatively review previous studies and discuss the quality of visualisations used in recent studies where visual impact of wind turbines has a high relevance.

We found that in recent literature, nine studies have not used any kind of visualisations, and two of these studies have only used text to describe one or more of the visual attributes in focus. Two studies opted for using relative visualisations to represent some of the visual attributes, and seven studies use generic visualisations to present all visual attributes, while three studies use them to present some of the visual attributes. Finally, four studies use site-specific visualisations for all visual attributes. Accordingly, even 
when looking at studies that are focused specifically on the acceptance of wind turbines, or the visual impact itself, the use of appropriate visualisations has not become standard practice.

The lesson to be learned is that the relevance and quality of any study that wants to address the economic significance of visual impacts, is directly associated to the scientific rigour with which the researchers create the scenario description and associated visualisations. From this perspective, carrying out a study that focuses on an elevated number of visual attributes without the necessary quality of the scenario description, might not yield solid scientific conclusions and gives less grounds for application in policy decisions and economic analysis. Because of this, if researchers are faced with resource and/or time constraints that make it infeasible to create high quality visualisations for all visual attributes under study, limiting the amount of these attributes while making sure that the remaining ones are correctly represented in the scenario description, will allow them obtain conclusions of much higher scientific value.

By arguing towards the relevance of visualisations on stated preference studies related to wind turbine visual disamenities from a theoretical standpoint, the need for rigorous and scientific formulation of them, and showing the relative lack of development in this area even on recent literature, this paper aims to raise the bar in regards to study design and to bring into discussion the relevance of visualisation for an accurate description of the scenarios considered.

\section{References}

4COffshore, 2016. Global offshore wind farms database.

Ackermann, N. M., 2014. How does landscape quality impact residents preferences for onshore wind farms in their community? - a choice experiment approach. Master's thesis, University of Copenhagen.

Álvarez-Farizo, B., Hanley, N., Jan. 2002. Using conjoint analysis to quantify public preferences over the environmental impacts of wind farms. An example from Spain. Energy Policy 30 (2), 107-116.

Arrow, K., Solow, R., 1993. Report of the NOAA panel on contingent valuation. Tech. rep., NOAA.

Bateman, I., Mawby, J., 2004. First impressions count: interviewer appearance and information effects in stated preference studies. Ecological Economics.

Bateman, I. J., Carson, R. T., Day, B., Hanemann, M., Hanley, N., Hett, T., Jones-Lee, M., Loomes, G., Mourato, S., Özdemiroglu, E., Pearce, D. W., Sugden, R., Swanson, J., et al Loomes, G., 2002. Economic valuation with stated preference techniques: a manual. Edward Elgar Publishing Ltd.

Betakova, V., Vojar, J., Sklenicka, P., 2015. Wind turbines location: How many and how far? Applied Energy.

Blomquist, G. C., Whitehead, J. C., 1998. Resource quality information and validity of willingness to pay in contingent valuation. Resource and Energy Economics 20 (2), 179-196.

Boatwright, J. A., 2013. Siting community wind farms: an investigation of nimby. Ph.D. thesis, Virginia Tech.

Börger, T., Hooper, T. L., Austen, M. C., 2015. Valuation of ecological and amenity impacts of an offshore windfarm as a factor in marine planning. Environmental Science \& Policy 54, 126-133.

Boyle, K., 2003. Contingent valuation in practice. A primer on nonmarket valuation.

Braga, J., Starmer, C., 2005. Preference anomalies, preference elicitation and the discovered preference hypothesis. Environmental and Resource Economics 32 (1), 55-89. 
Campbell, D., Aravena, C. D., Hutchinson, W. G., jun 2011. Cheap and expensive alternatives in stated choice experiments: are they equally considered by respondents? Applied Economics Letters 18 (8), 743-747.

Carlson, R., Chandler, P., Sweller, J., 2003. Learning and understanding science instructional material. Journal of educational psychology $95(3), 629$.

Carson, R., Mitchell, R., 1989. Using surveys to value public goods: The contingent valuation method. Resources for the Future, Washington DC.

Cerda, A., Garcia, L., Pastén, R., Damino, I., Diaz, M., 2014. The effects of visual information on willingness to pay for a recreational site improvement in chile. Innovar.

Champ, P., Boyle, K., Brown, T., 2012. A primer on nonmarket valuation. Kluwer Academics Publicshers.

Czajkowski, M., Hanley, N., LaRiviere, J., Simpson, K., 2014. What is the causal effect of information and learning about a public good on willingness to pay? Stirling Economics Discussion Paper.

Dimitropoulos, A., Kontoleon, A., 2009. Assessing the determinants of local acceptability of wind-farm investment: A choice experiment in the Greek Aegean Islands. Energy Policy 37 (5), 1842-1854.

EEA, 2009. Europe's onshore and offshore wind energy potential. Vol. 6.

Ek, K., 2006. Quantifying the environmental impacts of renewable energy: the case of Swedish wind power. In: Pearce, D. (Ed.), Environmental valuation in Developed Countries: Case Studies. Cheltenham, pp. 181-210.

Ek, K., Persson, L., sep 2014. Wind farms - Where and how to place them? A choice experiment approach to measure consumer preferences for characteristics of wind farm establishments in Sweden. Ecological Economics 105, 193-203.

Energistyrelsen, 2014. El produktionsomkostninger for 10 udvalgte teknologier, notat: 1-8. Tech. rep.

Ertac, S., 2011. Does self-relevance affect information processing? Experimental evidence on the response to performance and non-performance feedback. Journal of Economic Behavior \& Organization.

Franconeri, S., Simons, D., 2003. Moving and looming stimuli capture attention. Perception \& Psychophysics 65 (7), $999-1010$.

Georgiou, I., Areal, F. J., 2015. Economic valuation of an offshore wind farm in greece: The role of individuals' base-state influences and beliefs in the value formation process. Renewable and Sustainable Energy Reviews 52, 717-724.

Gibbons, S., 2015. Gone with the wind: Valuing the visual impacts of wind turbines through house prices. Journal of Environmental Economics and Management 72, 177-196.

Hevia-Koch, P. A., Ladenburg, J., 2015. Is willingness to pay for visualised landscape amenities sensitive to screen size when using web surveys? In: 33rd USAEE/IAEE North American Conference.

Hoehn, J., Randall, A., 2002. The effect of resource quality information on resource injury perceptions and contingent values. Resource and Energy Economics.

Hoehn, J. P., Lupi, F., Kaplowitz, M. D., 2010. Stated choice experiments with complex ecosystem changes: the effect of information formats on estimated variances and choice parameters. Journal of Agricultural and Resource Economics, 568590.

Hosking, J., du Preez, M., Sharp, G., 2013. Generating Guidance on Public Preferences for the Location of Wind Turbine Farms in the Eastern Cape. Magister commercii (statistics), Nelson Mandela Metropolitan University.

Israel, M., 2005. Services as experience goods: An empirical examination of consumer learning in automobile insurance. American Economic Review, 1444-1463.

Jacobsen, J., Boiesen, J., 2008. What's in a name? The use of quantitative measures versus 'Iconised'species when valuing biodiversity. Environmental and Resource Economics 39, 247-263.

Jensen, C. U., Panduro, T. E., Lundhede, T. H., oct 2014. The Vindication of Don Quixote: The Impact of Noise and Visual Pollution from Wind Turbines. Land Economics 90 (4), 668-682.

Kataria, M., Bateman, I., Christensen, T., Dubgaard, A., Hasler, B., Hime, S., Ladenburg, J., Levin, G., Martinsen, L., Nissen, C., 2012. Scenario realism and welfare estimates in choice experiments-a non-market valuation study on the european water 
framework directive. Journal of environmental management 94 (1), 25-33.

Knapp, L., Li, Y., Ma, Y., Rife, M., 2013. An Analysis of Offshore Wind Development: A Non-market, Stated-Preference Approach to Measure Community Perceptions and Opinions and Estimate Willingness. Master of science, University of Michigan.

Koundouri, P., Kountouris, Y., Remoundou, K., 2009. Valuing a wind farm construction: A contingent valuation study in Greece. Energy Policy 37 (5), 1939-1944.

Krueger, A., Parsons, G., Firestone, J., 2011. Valuing the visual disamenity of offshore wind power projects at varying distances from the shore: An application on the Delaware shoreline. Land Economics 87 (2), 268-283.

Ladenburg, J., 2014. Dynamic properties of the preferences for renewable energy sourcesA wind power experience-based approach. Energy.

Ladenburg, J., Bonnichsen, O., Dahlgaard, J. O., 2011. Testing the effect of a short cheap talk script in choice experiments. Nationaløkonomisk Tidsskrift 149, 25-54.

Ladenburg, J., Dubgaard, A., aug 2007. Willingness to pay for reduced visual disamenities from offshore wind farms in Denmark. Energy Policy 35 (8), 4059-4071.

Ladenburg, J., Jensen, K., Lassen, C., 2014. Does it matter why power outages occur? An example of information-induced gender-heterogeneous preference on the intensive and extensive margins of choice. Applied Economics Letters.

Ladenburg, J., Lutzeyer, S., dec 2012. The economics of visual disamenity reductions of offshore wind farms - Review and suggestions from an emerging field. Renewable and Sustainable Energy Reviews 16 (9), 6793-6802.

Ladenburg, J., Termansen, M., Hasler, B., 2013. Assessing acceptability of two onshore wind power development schemes: A test of viewshed effects and the cumulative effects of wind turbines. Energy 54, 45-54.

Landry, C. E., Allen, T., Cherry, T., Whitehead, J. C., jan 2012. Wind turbines and coastal recreation demand. Resource and Energy Economics 34 (1), 93-111.

LaRiviere, J., Czajkowski, M., Hanley, N., Aanesen, M., Falk-Petersen, J., Tinch, D., 2014. The value of familiarity: effects of knowledge and objective signals on willingness to pay for a public good. Journal of Environmental Economics and Management 68 (2), 376-389.

Lutzeyer, S., 2013. Essays in Offshore Wind Energy Development. Doctor of philosophy economics, North Carolina State University.

Maehr, A., Watts, G., Hanratty, J., Talmi, D., 2015. Emotional response to images of wind turbines: A psychophysiological study of their visual impact on the landscape. Landscape and Urban Planning.

Meyerhoff, J., Ohl, C., Hartje, V., jan 2010. Landscape externalities from onshore wind power. Energy Policy 38 (1), $82-92$.

Meyers-Levy, J., 1986. Gender differences in information processing: A selectivity interpretation. Ph.D. thesis, Northwestern University.

Mirasgedis, S., Tourkolias, C., Tzovla, E., Diakoulaki, D., 2014. Valuing the visual impact of wind farms: An application in South Evia, Greece. Renewable and Sustainable Energy Reviews 39, 296-311.

Navrud, S., Bråten, G., 2007. Consumers' Preferences for Green and Brown Electricity : A Choice Modelling Approach. Revue d'Économie Politique 117 (5), 795-811.

Palmer, J., 2015. Effect size as a basis for evaluating the acceptability of scenic impacts: Ten wind energy projects from Maine, USA. Landscape and Urban Planning.

Pohl, J., Faul, F., Mausfeld, R., 1999. Belästigung durch periodischen Schattenwurf von Windenergieanlagen. Tech. rep., jabr. Reed, C., Scott, W., 2014. Willingness-to-Pay for Renewable Wind Energy: Differences in Preferences Between Demographic Groups. Journal of Environmental and Resource Economics at Colby 1 (1).

Strazzera, E., Mura, M., Contu, D., 2012. Combining choice experiments with psychometric scales to assess the social acceptability of wind energy projects: A latent class approach. Energy Policy 48, 334-347. 
Sunak, Y., Madlener, R., 2016. The impact of wind farm visibility on property values: A spatial difference-in-differences analysis. Energy Economics 55, 79-91.

Teklay Abay, A., 2014. Economic Valuation of the Externalities of Offshore and Onshore Wind farms in Denmark: Results from a Nationwide Choice Experiment Survey. Msc, University of Copenhagen.

Tkac, J., 1998. The Effects of Information on Willingness-to-Pay Values of Endangered Species. American Journal of Agricultural Economics.

Vecchiato, D., 2014. How do you like wind farms? Understanding people's preferences about new energy landscapes with choice experiments. Aestimum, 15-37.

Westerberg, V., Jacobsen, J. B., Lifran, R., feb 2013. The case for offshore wind farms, artificial reefs and sustainable tourism in the French mediterranean. Tourism Management 34, 172-183.

Zehner, B., 2009. Interactive wind park planning in a visualization center - giving control to the user. In: Digital Landscape Architecture 2009, Proceedings of Presented Papers. pp. 16-23. 